\title{
Sistem Pengangkutan Sampah Berdasarkan Kapasitas Kendaraan Pengangkut dan Kondisi Kontainer Sampah di Surabaya Barat
}

\author{
Prismeida Putri Dara Ambariski dan Welly Herumurti \\ Jurusan Teknik Lingkungan, Fakultas Teknik Sipil dan Perencanaan, Institut Teknologi Sepuluh \\ Nopember (ITS) \\ Jl. Arief Rahman Hakim, Surabaya 60111 Indonesia \\ e-mail: herumurti@enviro.its.ac.id
}

\begin{abstract}
Abstrak-Sampah yang dihasilkan masyarakat Surabaya Barat sekitar 193,64 ton/hari yang tersebar di 52 TPS. Pengangkutan sampah dari TPS menuju TPA Benowo menggunakan 37 armada truk arm roll. Truk arm roll yang tersedia terdiri atastruk dengan kapasitas pengakutan $6 \mathrm{~m}^{3}, 8 \mathrm{~m}^{3}$ dan $14 \mathrm{~m}^{3}$ dengan kondisi kontainer tertutup dan tanpa tutup.Waktu kerja efektif yang ditetapkan DKP Kota Surabaya adalah 8 jam/hari. Namun, rata-rata waktu kerja yang dibutuhkan setiap sopir untuk melayani pengangkutan sampah di Surabaya Barat hanya sekitar 5 jam/hari.

Optimasi sisa waktu kerja dapat dilakukandengan penambahan jumlah ritasi yang dilakukan setiap hari. Optimasi dilakukan dengan mempertimbangkan aspek teknis berupa densitas sampah di TPS dan truk arm roll, serta waktu pengangkutan sampah. Optimasi penambahan ritasi dapat ditentukandengan memperhitungkan waktu off route dan sisa waktu kerja pada masing-masing sopir.

Penelitian rute terlebih dahulu dilakukan agar dapat mengetahui kondisi eksistingsistem pengangkutan sampah yang dioptimasi. Waktu pengangkutan sampah, jumlah ritasi, kapasitas kendaraan dan kondisi kontainer sampah memiliki pengaruh yang signifikan pada efektifitas sistem pengangkutan sampah.
\end{abstract}

Kata Kunci-Kapasitas pengangkutan, kontainer, optimasi, pengangkutan sampah dan truk arm roll.

\section{PENDAHULUAN}

$\mathrm{S}$ URABAYA Barat merupakan kawasan yang terus berkembang baik dari segi ekonomi, infrastruktur maupun permukiman [1]. Surabaya Barat terdiri dari tujuh kecamatan, antara lain Kecamatan Tandes, Kecamatan Sukomanunggal, Kecamatan Asemrowo, Kecamatan Benowo, Kecamatan Pakal, Kecamatan Lakarsantri dan Kecamatan Sambikerepdengan luas wilayah sebesar 116,39 $\mathrm{m}^{2}$ [2].

Faktor utama yang mempengaruhi pengangkutan sampah adalah kepadatan penduduk, kuantitas dan kualitas sampah, karakteristik dan area pelayanan serta beberapa hal lain yang dibahas adalah jarak dan jaringan jalan, pola pengangkutan, jenis kendaraan, frekuensi, tingkat pelayanan beserta tenaga kerja [3]-[4]. Jumlah penduduk di Surabaya Barat pada tahun 2014 sebanyak 452.324 jiwa dengan pertumbuhan penduduk sebesar $0,7 \%$ per tahun [2].Berdasarkan hasil penelitian terdahulu, laju timbulan sampah yang dihasilkan per orang untuk setiap harinya di Surabaya Barat sebesar 0,27 $\mathrm{kg}$ /orang.hari [5].Semakin besar pertumbuhan ekonomi dan persentase jumlah penduduk, maka semakin besar pula jumlah timbulan sampah yang dihasilkan [6]-[7]-[8].

Daya angkut sampah di Surabaya Barat yang ada saat ini sekitar 169,8 ton/hari dengan tingkat pelayanan mencapai $84,84 \%$. Banyak penelitian di lingkungan perkotaan telah mengungkapkan bahwa efisiensi pengangkutan sampah dipengaruhi oleh ketersedian tenaga kerja dan kapasitas pengangkutan [9].Sebanyak 52 TPS yang terdiri dari 44 TPS jenis transfer depo dan 8 TPS jenis landasan tersebar di Surabaya Barat.Truk arm roll yang tersedia untuk operasional pengangkutan sampah di Surabaya Barat terdiri ataskapasitas $6 \mathrm{~m}^{3}$ sebanyak 5 armada, $8 \mathrm{~m}^{3}$ sebanyak 13 armada dan $14 \mathrm{~m}^{3}$ sebanyak 19 armada[10].

Beberapa faktor yang harus diperbaiki DKP Kota Surabaya selaku dinas terkait agar mampu mengangkut semua sampah yang dihasilkan dari daerah pelayanan setiap harinya. Salah satunya berkaitan dengan manajemen dan pendanaan yang tidak memadai serta kurangnya teknologi dan kendaraan pengangkut.Dengan jumlah sarana kendaraan yang terbatas, maka penggunaan kendaraan dari aspek teknis perlu dioptimumkan. Optimasi pengangkutan sampah dapat dilakukan dengan perencanaan rute berdasarkan pada keseimbangan kapasitas setiap kendaraan dan timbulan sampah yang dikumpulkan dari TPS serta jumlah ritasi yang disesuaikan dengan waktu kerja [8]. Diharapkan dengan adanya optimasi, pelayanan pengangkutan sampah di Surabaya Barat dapat ditingkatkan.

\section{METODE PENELITIAN}

\section{A. Pengumpulan Data}

Data yang dibutuhkan dalam penelitian ini antara lain data sekunder dan data primer.

\section{Pengumpulan Data Sekunder}

Data sekunder yang dibutuhkan dalam penelitian ini dapat diperoleh dari Badan Pusat Statistik (BPS) Kota Surabaya dan Dinas Kebersihan dan Pertamanan (DKP) Kota Surabaya. Data sekunder yang diperlukan dalam penelitian ini meliputi peta wilayah studi,data kependudukan,area pelayanan 
pengangkutan sampah, data timbulan sampah, jumlah, kapasitas dan spesifikasi armada pengangkut sampah, rute dan jumlah trip pengangkutan sampah dari TPS menuju TPA, lokasi, jumlah dan jenis TPS serta jumlah kontainer dan kapasitas tiap TPS.

\section{Pengumpulan Data Primer}

Metode yang digunakan dalam pengumpulan data primer adalah dengan melakukan pengukuran dan pengamatan langsung pada sistem pengangkutan sampah di Surabaya Barat. meliputi:

a) Metode pengukuran densitas sampah di TPS

b) Metode survei lapangan untuk mengetahui massa sampah yang diangkut dari TPS menuju TPA

c) Metode survei lapangan tentang pengangkutan sampah dan densitas berdasarkan kapasitas kendaraan pengangkut dan kondisi kontainer sampah

\section{B. Penentuan Sampel}

Pada penelitian ini sebanyak $30 \%$ dari total truk arm roll yang digunakan untuk operasional pengangkutan sampah di Surabaya Barat dijadikan sampel. Pemilihan sampel truk arm roll ini didasarkan pada kapasitas truk, ritasi truk, jenis TPS yang dilayani, jarak TPS ke TPA serta umur truk. Rincian sampel truk yang digunakan dapat dilihat pada Tabel1.

Tabel 1.

Truk Arm Roll yang Dijadikan Sampel Penelitian

\begin{tabular}{ccccl}
\hline No & Kapasitas Kontainer & $\begin{array}{c}\text { Nomor } \\
\text { Kendaraan }\end{array}$ & $\begin{array}{c}\text { Tahun } \\
\text { Pembelian }\end{array}$ & $\begin{array}{c}\text { Merk } \\
\text { Kendaraan }\end{array}$ \\
\cline { 2 - 3 } 1 & $\left(\mathrm{~m}^{3}\right)$ & L 9019 RP & 2007 & Isuzu Elf \\
2 & 6 & L 9001 XP & 2007 & Isuzu Elf \\
3 & 6 & L 9048 VP & 2007 & Isuzu Elf \\
4 & 6 & L 8071 QP & 1995 & Toyota Ryno \\
5 & 8 & L 8005 NP & 1995 & Toyota Ryno \\
6 & 8 & L 9485 NP & 2014 & Hino Dutro \\
7 & 8 & L 9487 NP & 2014 & Hino Dutro \\
8 & 14 & L 8055 QP & 2002 & Isuzu Borneo \\
9 & 14 & L 8075 QP & 1995 & Nissan \\
10 & 14 & L 8022 SP & 2002 & Isuzu Borneo \\
11 & 14 & L 8021 TP & 2002 & Isuzu Borneo \\
12 & 14 & L 8011 SP & 2002 & Isuzu Borneo \\
\hline
\end{tabular}

Penentuan lokasi TPS yang menjadi sampel didasarkan pada beberapa pertimbangan yaitu kapasitas kontainer di setiap TPS $\left(6 \mathrm{~m}^{3}, 8 \mathrm{~m}^{3}\right.$ dan $\left.14 \mathrm{~m}^{3}\right)$, jenis kontainer, wilayah pelayanan dan massa sampah di kontainer yang diangkut menuju TPA Benowo. Jumlah TPS yang dijadikan sampel pada penelitian ini sebanyak 9 TPS. Rincian TPS yang diteliti dapat dilihat pada Tabel 2.
TPSyang Dijadikan Sampel Penelitian

\begin{tabular}{|c|c|c|c|c|}
\hline \multirow[t]{2}{*}{ No } & \multirow[t]{2}{*}{ Nama TPS } & $\begin{array}{l}\text { Kapasitas } \\
\text { Kontainer } \\
\end{array}$ & \multirow{2}{*}{$\begin{array}{l}\text { Kondisi } \\
\text { Kontainer }\end{array}$} & \multirow{2}{*}{$\begin{array}{c}\text { Lokasi } \\
\text { Kecamatan }\end{array}$} \\
\hline & & $\left(\mathrm{m}^{3}\right)$ & & \\
\hline 1 & TPS Graha Suryanata & 6 & Tertutup & Pakal \\
\hline 2 & TPS Kuwukan & 6 & Tanpa Tutup & Sambikerep \\
\hline 3 & TPS Lidah Wetan & 6 & Tanpa Tutup & Lakarsantri \\
\hline 4 & TPS Oso Wilangon & 8 & Tertutup & Asemrowo \\
\hline 5 & TPS Manukan Telaga & 8 & Tanpa Tutup & Tandes \\
\hline 6 & $\begin{array}{l}\text { TPS Pondok Benowo } \\
\text { Indah }\end{array}$ & 14 & Tanpa Tutup & Pakal \\
\hline 7 & TPS Simo Rukun & 14 & Tanpa Tutup & Sukomanunggal \\
\hline 8 & TPS Kandangan & 14 & Tanpa Tutup & Benowo \\
\hline 9 & TPS Putat Gede & 14 & Tanpa Tutup & Sukomanunggal \\
\hline
\end{tabular}

\section{Analisis Data dan Pembahasan}

Berdasarkan data primer dan sekunder yang telah diperoleh, dapat dilakukan analisis dan pembahasan. Data yang diolah merupakan perhitungan timbulan, densitas sampah, waktu pengangkutan sampah hasil penelitian rute truk arm roll.

\section{Densitas Sampah}

Karakteristik sampah yang diukur meliputi volumedan massa sampah. Volume sampah diperoleh dari hasil pengukuran terhadap volume tiap gerobak yang masuk ke TPS. Massa sampah di gerobak diperoleh dari penimbangan dengan timbangan pegas. Melalui data tersebut, selanjutnya dapat dihitung densitas sampah.Densitas sampah pada truk arm roll dianalisis berdasarkan kapasitas kontainer yang ada $\left(6 \mathrm{~m}^{3}, 8 \mathrm{~m}^{3}\right.$, dan $\left.14 \mathrm{~m}^{3}\right)$ dan kondisi kontainer (tertutup dan tanpa tutup) di setiap TPS. Densitastersebutdihitung dengan cara menghitungdata input berat sampah yang masuk ke TPS dari jembatan timbang TPA dan dibagi dengan volume truk (Weight Volume Analysis).Densitas sampah dihitung untuk menentukan faktor kompaksi pengangkutan sampah sehingga dapat digunakan untuk optimasimassasampah yang bisa diangkut oleh truk untuk sekali ritasi.

\section{Waktu Pengangkutan Sampah}

Waktu pengangkutan sampah dapat ditentukan daripenelitian rute pengangkutan sampah sebanyak 2-3 kali untuk masing-masing truk arm roll kapasitas $6 \mathrm{~m}^{3}, 8 \mathrm{~m}^{3}$ dan $14 \mathrm{~m}^{3}$, yakni 2 pada hari kerja (Senin-Jumat) dan 1 pada hari libur (Sabtu-Minggu dan Hari Besar). Data yang perlu diambil antara lain waktu pengangkutan (uc, pc, s, dbc, h, w), jarak antar lokasi, rute pengangkutan, kecepatan rata-rata, spesifikasi alat angkut, berat penimbangan sampah di TPA, dan data pendukung lainnya. Analisis dan pembahasan yang dilakukan dalam pengangkutan sampah ini yaitu untuk menghitung jumlah ritasi (efisiensi pengangkutan) yang dapat ditentukandari keefektifan waktu pengangkutan dari masing masing truk pengangkut sampah. Klasifikasi waktu pengangkutan sampah dapat dilihat pada Tabel 3. 


\begin{tabular}{ll}
\hline T pengangkutan ( $\mathrm{t})$ & $\mathrm{t}$ pool ke lokasi pertama (t1) \\
& $\mathrm{t}$ dari TPA ke pool (t2) \\
& $\mathrm{t}$ dari TPS ke pool (t2) \\
& $\mathrm{t}$ dari TPS ke TPS (dbc) \\
& $\mathrm{t}$ menurunkan kontainer di TPS (uc) \\
& $\mathrm{t}$ menaikkan kontainer di TPS (pc) \\
& $\mathrm{t}$ memasang terpal di TPS (pc) \\
& $\mathrm{t}$ dari TPS ke TPA (h1) \\
& $\mathrm{t}$ dari TPA ke TPS (h2) \\
\hline $\mathrm{t}$ TPA untuk unloading (s) & $\mathrm{t}$ TPA penimbangan \\
& $\mathrm{t}$ jalan di TPA \\
& $\mathrm{t}$ unloading di TPA \\
& $\mathrm{t}$ buka terpal di TPA \\
\hline $\mathrm{t}$ operasional (t-ops) & $\mathrm{t}$ warming up \\
& $\mathrm{t}$ antri isi BBM \\
& $\mathrm{t}$ isi BBM di SPBU \\
\hline $\mathrm{t}$-off & $\mathrm{t}$ TPA antri penimbangan \\
\hline $\mathrm{t}$ hambatan (t-ham) $(\mathrm{w})$ & $\mathrm{t}$ TPA antri zona unloading \\
& Kerusakan pada kendaraan \\
\hline $\mathrm{t}$ istirahat dan makan sopir \\
$\mathrm{t}$ non produktif TPS \\
$\mathrm{t}$ kelebihan jam istirahat \\
$\mathrm{t}$ hambatan (t-ham) \\
\hline Menunggu jam pulang (di kantor) \\
\hline
\end{tabular}

\section{HASIL DAN PEMBAHASAN}

\section{A. Kondisi Eksisting Pengangkutan Sampah di Surabaya Barat}

Sampah di Surabaya Barat baik yang berasal dari wilayah permukiman, fasilitas umum maupun pasar dikelola oleh Dinas Kebersihan dan Pertamanan (DKP) Kota Surabaya. Lokasi antara TPS di Surabaya Barat dan TPA Benowo relatif dekat, jarak terdekat hanya sejauh $4 \mathrm{~km}$ dari TPA Benowo sedangkan jarak terjauh yaitu $20 \mathrm{~km}$.

\section{Massa Sampah}

Massa sampah didapatkan dari hasil penimbangan di jembatan timbang yang ada di TPA Benowo selama satu bulan pengamatan. Massa sampah yang dihasilkan Kota Surabaya setiap harinya yang masuk ke TPA Benowo sebanyak 1519,76 ton/hari. Rata-rata massa sampah dari wilayah Surabaya Barat yang masuk ke TPA Benowo per harinya yaitu sebesar 169,80ton/hari.Persentase massa sampah yang masuk ke TPA Benowo per hari berdasarkan kecamatan dapat dilihat pada Gambar 1.

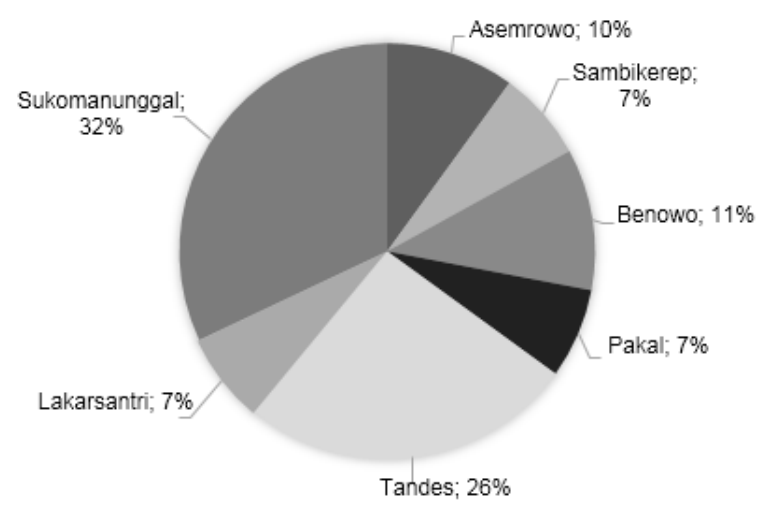

Gambar 1.Persentase Massa Sampah Berdasarkan Kecamatan

\section{Pelayanan Pengangkutan Sampah}

Persentase pelayanan sistem pengangkutan sampah yang telah berjalan saat ini dapat ditentukan dengan membandingkan jumlah sampah yang masuk ke TPA Benowo dengan jumlah timbulan yang masuk di setiap TPS. Tingkat pelayanan pengangkutan sampah di Surabaya Barat sudah mencapai target RPJMN, dengan persentase pelayanan saat ini yaitu sekitar $84,84 \%$. Persentase pelayanan pengangkutan sampah di Surabaya Barat selengkapnya dapat dilihat pada Tabel 4.

Tabel 4.

Persentase Pelayanan Pengangkutan Sampah di Surabaya Barat

\begin{tabular}{llccc}
\hline \multirow{2}{*}{ No } & Kecamatan & $\begin{array}{c}\text { Rata-Rata Berat } \\
\text { Sampah yang } \\
\text { Masuk ke TPA } \\
\text { Benowo }\end{array}$ & $\begin{array}{c}\text { Jumlah } \\
\text { Timbulan } \\
\text { Sampah di } \\
\text { TPS }\end{array}$ & $\begin{array}{c}\text { Persentase } \\
\text { Pelayaan }\end{array}$ \\
\cline { 3 - 5 } & & (kg/hari) & (kg/hari) & $(\%)$ \\
\hline 1 & Tandes & 45058,75 & 50551,74 & $89,13 \%$ \\
2 & Benowo & 19558,75 & 21714,87 & $90,07 \%$ \\
3 & Pakal & 11722,50 & 13345,98 & $87,84 \%$ \\
4 & Sukomanunggal & 54233,75 & 57814,05 & $93,81 \%$ \\
5 & Lakarsantri & 11280,00 & 16201,21 & $69,62 \%$ \\
6 & Sambikerep & 11442,50 & 14548,86 & $78,65 \%$ \\
7 & Asemrowo & 16498,75 & 19460,72 & $84,78 \%$ \\
\hline & Jumlah & 169795,00 & 193637,43 & $84,84 \%$ \\
\hline
\end{tabular}

\section{B. Waktu Pengangkutan Sampah di Surabaya Barat}

Waktu pengangkutan sampah seringkali dipengaruhi oleh beberapa faktor, yaitu rute pengangkutan, kecepatan kendaraan, jumlah ritasi, tipe jalan dan aktivitas di TPA. Waktu yang diperlukan untuk pengangkutan sampah pada masing-masing kendaraan diukur dengan menggunakan stopwatch. Pemerataan dan perhitungan kembali terhadap jarak tempuh masing-masing sopir truk arm roll diperlukan agar dapat menghindari kelebihan waktu kerja pada sopir tertentu.Berdasarkan pembagian waktu yang telah dibuat, dapat ditentukan waktu yang dibutuhkan masing-masing kendaraan untuk operasional pengangkutan sampah setiap hari. Waktu pengangkutan sampah hasil penelitian rute dapat dilihat pada Tabel 5. 
Tabel 5.

Total Waktu Pengangkutan Sampah Hasil Penelitian Rutedi Surabaya Barat

\begin{tabular}{|c|c|c|c|c|c|c|c|c|c|c|}
\hline \multirow{3}{*}{$\begin{array}{l}\text { Nomor } \\
\text { Kendaraan }\end{array}$} & \multirow{3}{*}{$\begin{array}{c}\text { Kapasitas } \\
\text { Kontainer } \\
\left(\mathrm{m}^{3}\right)\end{array}$} & \multicolumn{3}{|c|}{ Jam Kerja (Lapangan) } & \multirow[b]{2}{*}{ t-off } & \multirow{2}{*}{$\begin{array}{c}\text { Total } \\
\text { Jam } \\
\text { Kerja }\end{array}$} & \multirow{2}{*}{$\begin{array}{c}\text { Jam } \\
\text { Kerja } \\
\text { DKP }\end{array}$} & \multicolumn{2}{|c|}{ Waktu Off Route } & \multirow{2}{*}{$\begin{array}{c}\text { Sisa } \\
\text { Waktu } \\
\text { Kerja }\end{array}$} \\
\hline & & $\mathrm{t}$ & $\mathrm{s}$ & t-ops & & & & $\begin{array}{c}\text { Non } \\
\text { Produktif }\end{array}$ & t-ham & \\
\hline & & (jam) & (jam) & (jam) & (jam) & (jam) & (jam) & (jam) & (jam) & (jam) \\
\hline L 9019 RP & 6 & 3,096 & 0,438 & 0,070 & 0,507 & 3,605 & 8 & 1,054 & 1,165 & 2,176 \\
\hline L 9001 XP & 6 & 3,487 & 0,533 & 0,090 & 0,000 & 4,110 & 8 & 0,000 & 0,219 & 3,672 \\
\hline L 9048 VP & 6 & 3,222 & 0,373 & 0,106 & 0,331 & 3,700 & 8 & 0,042 & 0,116 & 4,143 \\
\hline L 8071 QP & 8 & 2,996 & 0,421 & 0,074 & 0,923 & 3,492 & 8 & 0,075 & 1,023 & 3,410 \\
\hline L 8005 NP & 8 & 3,116 & 0,457 & 0,118 & 0,301 & 3,692 & 8 & 0,162 & 0,431 & 3,715 \\
\hline L 9485 NP & 8 & 7,558 & 0,944 & 0,105 & 1,110 & 8,606 & 8 & 0,297 & 0,198 & $-0,991$ \\
\hline L 9487 NP & 8 & 4,684 & 0,379 & 0,267 & 0,555 & 5,330 & 8 & 0,261 & 0,421 & 1,988 \\
\hline L 8055 QP & 14 & 4,012 & 0,690 & 0,127 & 0,336 & 4,829 & 8 & 0,272 & 0,401 & 2,499 \\
\hline L 8075 QP & 14 & 4,784 & 0,543 & 0,147 & 1,238 & 5,474 & 8 & 0,238 & 0,203 & 2,323 \\
\hline L 8022 SP & 14 & 2,837 & 0,569 & 0,122 & 0,305 & 3,527 & 8 & 0,085 & 0,178 & 4,211 \\
\hline L 8021 TP & 14 & 3,800 & 0,502 & 0,142 & 0,671 & 4,444 & 8 & 0,280 & 0,074 & 3,204 \\
\hline L $8011 \mathrm{SP}$ & 14 & 3,711 & 0,457 & 0,324 & 0,611 & 4,491 & 8 & 0,325 & 0,098 & 3,087 \\
\hline
\end{tabular}

Rata-rata sopir memiliki kelebihan sisa waktu kerja, hal tersebut dapat dioptimasi dengan pengaturan jarak tempuh dan penambahan jumlah ritasi. Truk dengan nomor kendaraan L 9485 NP memiliki keadaan anomali, karena waktu kerja yang dibutuhkan untuk melayani pengangkutan sampah pada daerah pelayanan truk tersebut melebihi jam kerja yang ditetapkan DKP Kota Surabaya. Sementara itu, faktor off route pada masing-masing sopir dapat dilihat pada Tabel 6.

Tabel 6.

Faktor Off Route Sopir di Surabaya Barat

\begin{tabular}{ccccc}
\hline & & & & \\
Kenor & $\begin{array}{c}\text { Kapasitas } \\
\text { Kontainer }\end{array}$ & $\begin{array}{c}\text { Jam Kerja } \\
\text { DKP }\end{array}$ & $\begin{array}{c}\text { Waktu Off } \\
\text { Route }\end{array}$ & $\begin{array}{c}\text { Faktor Off } \\
\text { Route }\end{array}$ \\
\cline { 2 - 3 } & & & & \\
\cline { 2 - 3 } L 9019 RP & 6 & 8 & 2,219 & 0,28 \\
L 9001 XP & 6 & 8 & 0,219 & 0,03 \\
L 9048 VP & 6 & 8 & 0,157 & 0,02 \\
L 8071 QP & 8 & 8 & 1,098 & 0,14 \\
L 8005 NP & 8 & 8 & 0,593 & 0,07 \\
L 9485 NP & 8 & 8 & 0,495 & 0,06 \\
L 9487 NP & 8 & 8 & 0,682 & 0,09 \\
L 8055 QP & 14 & 8 & 0,672 & 0,08 \\
L 8075 QP & 14 & 8 & 0,441 & 0,06 \\
L 8022 SP & 14 & 8 & 0,263 & 0,03 \\
L 8021 TP & 14 & 8 & 0,353 & 0,04 \\
L 8011 SP & 14 & 8 & 0,422 & 0,05 \\
\hline Rata-Rata & & & 0,800 & 0,08 \\
\hline
\end{tabular}

Tabel 6 menunjukkan rata-rata faktor off route para sopir yang melayani pengangkutan sampah di Surabaya Barat sebesar 0,08. Nilai tersebut kurang dari nilai toleransi yang sudah ditetapkan antara 0,1-0,15 [11]. Dapat disimpulkan bahwa waktu kerja para sopir yang melayani pengangkutan sampah di Surabaya Barat termasuk dalam kategori produktif.

\section{Densitas Sampah}

Perhitungan tentang densitas sampah di TPS dan kendaraan pengangkut sampah sangat penting dilakukan untuk mengetahui faktor kompaksi sampah. Kebutuhan desain awal densitas sampah di gerobak sampah yaitu $200-350 \mathrm{~kg} / \mathrm{m}^{3}$ [12]. Data hasil pengukuran densitas sampah di TPS dapat dilihat pada Tabel 7.

Tabel 7. Densitas Sampah di TPS

\begin{tabular}{|c|c|c|}
\hline \multirow{2}{*}{ No } & \multirow{2}{*}{ Nama TPS } & Densitas Sampah di Gerobak \\
\hline & & $\left(\mathrm{kg} / \mathrm{m}^{3}\right)$ \\
\hline 1 & TPS Tambak Oso Wilangon & 188,80 \\
\hline 2 & TPS Kuwukan & 232,09 \\
\hline 3 & TPS Putat Gede & 227,43 \\
\hline 4 & TPS Pondok Benowo Indah & 197,19 \\
\hline 5 & TPS Kandangan & 196,90 \\
\hline 6 & TPS Lidah Wetan & 152,87 \\
\hline 7 & TPS Graha Suryanata & 201,87 \\
\hline 8 & TPS Simo Rukun & 230,84 \\
\hline 9 & TPS Manukan Telaga & 227,12 \\
\hline & Rata-Rata & 206,12 \\
\hline
\end{tabular}


Densitas sampah di kendaraan pengangkut sampah dihitung berdasarkan kapasitas dan kondisi kontainer. Kapasitas kendaraan pengangkut sampah terdiri dari $6 \mathrm{~m}^{3}, 8 \mathrm{~m}^{3}$ dan 14 $\mathrm{m}^{3}$, sedangkan untuk kondisi kontainer terdiri dari kontainer tertutup dan tanpa tutup. Densitas pada setiap kapasitas truk arm roll dan kondisi kontainer yang digunakan untuk melayani pengangkutan sampah di Surabaya Baratdapat dilihat pada Tabel 8.

Tabel 8.

Densitas Sampah Berdasarkan Kapasitas Kendaraan Pengangkut dan Kondisi Kontainer Sampah

\begin{tabular}{ccc}
\hline Kapasitas Kontainer & Densitas Sampah di Setiap Kondisi Kontainer \\
\hline$\left(\mathrm{m}^{3}\right)$ & Tanpa Tutup & Tertutup \\
\hline 6 & 403,21 & 278,33 \\
8 & 409,33 & 275,70 \\
14 & 356,19 & 214,06 \\
\hline
\end{tabular}

Berdasarkan pengamatan di lapangan, densitas sampah akan tergantung pada sarana pengangkut yang digunakan. Biasanya untuk kebutuhan desain densitas sampah di truk yaitu 250 $400 \mathrm{~kg} / \mathrm{m}^{3}$ [12]. Tabel 8 menunjukkan bahwa kapasitas kendaraan pengangkut tidak mempengaruhi densitas sampah secara signifikan. Tetapi berbeda halnya apabila dibandingkan dengan kondisi kontainer, kontainer tanpa tutup memiliki densitas lebih besar daripada kondisi kontainer tertutup. Hal tersebut menandakan sampah yang dapat ditampung kontainer tertutup lebih sedikit sehingga penggunaan kontainer tertutup kurang efisien untuk TPS yang memiliki laju timbulan sampah yang besar.Namun, karena rata-rata sampah yang dapat ditampung kontainer tertutup sedikit membuat waktu operasional yang dibutuhkan truk arm roll dengan kontainer tertutup lebih cepat daripada kontainer tanpa tutup. Perbedaan tersebut terdapat pada waktu yang dibutuhkan untuk membongkar sampah di TPA serta waktu untuk membuka dan menutup terpal. Perbedaan kontainer tanpa tutup dan tertutup dapat dilihat pada Gambar 2. (a)

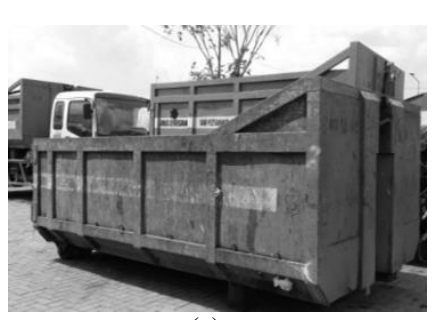

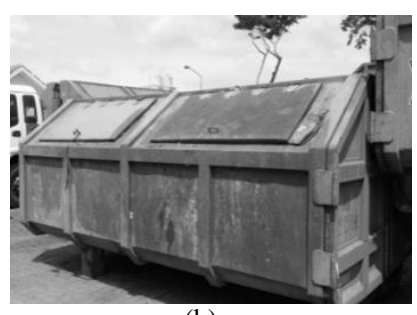

(b)
Gambar 2. (a) Kontainer Tanpa Tutup dan (b) Kontainer Tertutup

\section{Optimasi Penambahan Ritasi}

Optimasi penambahan ritasi perlu dilakukan agar sarana dan prasarana yang menunjang pelayanan pengangkutan sampah dapat dimanfaatkan semaksimal mungkin.Ritasi yang dapat ditambahkan pada setiap truk arm roll dapat dilihat pada Tabel 9. Penambahan jumlah ritasi guna untuk mengurangi sisa waktu kerjadapat dihitung dengan Persamaan 1 sebagai berikut:

$\mathrm{Nd}=[\mathrm{H}(1-\mathrm{W})-(\mathrm{t} 1+\mathrm{t} 2)] / \mathrm{T}_{\mathrm{HC}}$

Dimana

$$
\begin{aligned}
& \mathrm{Nd}=\text { jumlah trip, trip/hari } \\
& \mathrm{H}=\text { waktu kerja perhari, jam } \\
& \mathrm{t} 1 \text { = waktu dari garasi ke lokasi pertama } \\
& \mathrm{t} 2 \quad \text { = waktu dari lokasi terakhir ke garasi } \\
& \mathrm{T}_{\mathrm{HCS}}=\text { waktu pengangkutan per trip } \\
& \mathrm{W} \quad=\text { faktor } \text { off route }
\end{aligned}
$$

\begin{tabular}{|c|c|c|c|c|c|c|c|c|c|}
\hline \multirow{2}{*}{$\begin{array}{c}\text { Nomor } \\
\text { Kendaraan }\end{array}$} & \multirow{2}{*}{$\begin{array}{l}\text { Kapasitas } \\
\text { Kontainer } \\
\quad\left(\mathrm{m}^{3}\right)\end{array}$} & $\mathrm{H}$ & $(1-\mathrm{W}) \mathrm{H}$ & $\mathrm{P}$ & $\mathrm{T}$ & $\mathrm{t} 1$ & $\mathrm{t} 2$ & $\begin{array}{c}\text { Ritasi } \\
\text { Eksisting }\end{array}$ & \multirow{2}{*}{$\begin{array}{c}\mathrm{Nd} \\
\text { (rit/hari) }\end{array}$} \\
\hline & & (jam/hari) & & (jam) & (jam) & (jam) & (jam) & (rit/hari) & \\
\hline L 9019 RP & 6 & 8 & 6,800 & 0,081 & 1,197 & 0,458 & 0,683 & 2 & 5 \\
\hline L 9001 XP & 6 & 8 & 6,800 & 0,211 & 1,295 & 0,513 & 0,917 & 2 & 4 \\
\hline L 9048 VP & 6 & 8 & 6,800 & 0,073 & 1,045 & 0,673 & 0,817 & 2 & 5 \\
\hline L 8071 QP & 8 & 8 & 6,800 & 0,095 & 1,325 & 0,348 & 0,860 & 2 & 4 \\
\hline L 8005 NP & 8 & 8 & 6,800 & 0,080 & 1,030 & 0,649 & 0,865 & 3 & 5 \\
\hline L 9485 NP & 8 & 8 & 6,800 & 0,145 & 1,822 & 0,536 & 0,676 & 4 & 3 \\
\hline L 9487 NP & 8 & 8 & 6,800 & 0,070 & 1,735 & 0,467 & 0,570 & 2 & 3 \\
\hline L 8055 QP & 14 & 8 & 6,800 & 0,096 & 1,240 & 0,473 & 0,658 & 3 & 5 \\
\hline L 8075 QP & 14 & 8 & 6,800 & 0,134 & 1,859 & 0,886 & 0,724 & 2 & 3 \\
\hline L 8022 SP & 14 & 8 & 6,800 & 0,096 & 0,943 & 0,591 & 0,929 & 2 & 6 \\
\hline L $8021 \mathrm{TP}$ & 14 & 8 & 6,800 & 0,150 & 1,661 & 0,347 & 0,634 & 2 & 4 \\
\hline L 8011 SP & 14 & 8 & 6,800 & 0,077 & 1,564 & 0,309 & 0,731 & 2 & 4 \\
\hline Rata-Rata & & & & & & & & 2 & 4 \\
\hline
\end{tabular}

Tabel 9.

Optimasi Penambahan Ritasi Truk Arm Roll Hasil Penelitian Rute 
Agar tercapai optimasi jumlah ritasi setiap harinya, diasumsikan faktor off route yang digunakan dalam perhitungan yaitu 0,15. Rata-rata efisiensi jumlah ritasi yang dapat dilakukan oleh setiap truk arm roll di Surabaya Barat yaitu 4 rit/hari, sedangkan jumlah ritasi eksisting hanya 2 rit/hari. Diperlukan penambahan ritasi pada setiap truk arm roll sebanyak 2 rit/hari. Pengaturan penambahan rute baru harus dibuat dengan memperhatikan pemerataan waktu kerja dan jarak tempuh.Adanya penambahan ritasi ini diharapkan dapat memperbaiki efektifitas pengangkutan dan pelayanan pengangkutan sampah juga semakin meningkat.

\section{KESIMPULAN/RINGKASAN}

Sisa waktu kerja dapat dimanfaatkan dengan perencanaan ulang jumlah ritasi pada setiap truk arm roll. Perubahan jumlah ritasi akan berpengaruh pada jumlah kendaraan yang digunakan untuk operasional dan biaya pengangkutan sampah. Selain itu, penggunaan kondisi kontainer tanpa tutup dapat menampung lebih banyak sampah daripada kontainer tertutup. Kapasitas kendaraan dan kondisi kontainer sampah juga berpengaruh pada biaya pengangkutan sampah. Optimasi sistem pengangkutan sampah berdasarkan kapasitas kendaraan pengangkut dan kondisi kontainer sampah yang diberikan telah disesuaikan dengan ketersediaan sarana dan prasarana yang dimiliki oleh DKP Kota Surabaya.Diharapkan dengan adanya optimasi ini dapat digunakan sebagai informasi pendukung dalam rangka peningkatan pelayanan sistem pengangkutan sampah di Surabaya Barat.

\section{UCAPAN TERIMA KASIH}

Penulis mengucapkan terima kasih kepada Dinas Kebersihan dan Pertamanan Kota Surabaya atas kerjasamanya, sehingga penelitian ini dapat diselesaikan. Ucapan ini dikhususkan pada sopir truk arm roll, petugas di TPS dan pegawai dinas yang ada di Pool Tanjungsari.

\section{DAFTAR PUSTAKA}

[1] A.K. Ghana dan A.M. Navastara, "Pengaruh perkembangan permukiman terhadap dinamika harga lahan di Surabaya Barat,"Jurnal Teknik Pomits, Vol. 1, No.1 (2012) 1-8.

[2] Badan Pusat Statistik Kota Surabaya,"Kota Surabaya Dalam Angka," Kota Surabaya (2015)

[3] G. Greco, M. Allegrini, C. Del Lungo, P.Gori Savellini, dan L. Gabellini, "Drivers of solid waste collection costs. Empirical evidence from Italy,"Journal of Cleaner Production, Vol. 106 (2015) 364-371.

[4] Y. T. Huang, T. C. Pan, dan J. J. Kao, "Performance assessment for municipal solid waste collection in Taiwan,"Journal of Environmental Management, Vol. 92, No. 4 (2011) 1277-1283.

[5] S. Kurniawati, "Peningkatan reduksi sampah rumah tangga di Kecamatan Sukomanunggal," belum dipublikasikan.

[6] S.Das, dan B.K.Bhattacharyya, "Optimization of municipal solid waste collection and transportation routes,"Waste Management, Vol. 43 (2015) 9-18.

[7] Y. Dhokhikah, Y.Trihadiningrum dan S. Sunaryo, "Community participation in household solid waste reduction in Surabaya, Indonesia,"Resources, Conservation and Recycling, Vol. 102 (2015) 153-162.

[8] N.P. Thanh, Y. Matsui, N.V.C. Ngan, N.H. Trung, T.Q.Vinh dan N.T.H. Yen, "GIS application for estimating the current status and improvement on municipal solid waste collection and transport system: case study at
Can Tho City, Vietnam,"As. J. Energy Env, Vol. 10,No. 2 (2009) 108121.

[9] M. Sharholy, K. Ahmad, G. Mahmood dan R.C.Trivedi, "Municipal solid waste management in Indian Cities - A review,"Waste Management, Vol. 28, No. 2(2008) 459-467.

[10] Dinas Kebersihan dan Pertamanan Kota Surabaya, "Jumlah dan spesifikasi kendaraan pengangkut sampah tahun 2015," (2015).

[11] G. Tchobanoglous, H. Theisen dan S. Vigil,"Intregated solid waste management," New York: McGraw-Hill International (1993).

[12] E. Damanhuri, “Teknik Pembuangan Akhir," Bandung: Jurusan Teknik Lingkungan ITB (2008). 